\title{
REKAYASA MODEL APLIKASI SISTEM PRODUCT KNOWLADGE UNTUK MENDUKUNG PENGAMBILAN KEPUTUSAN DALAM MENENTUKAN KINERJA KARYAWAN
}

\author{
Junaidi ${ }^{1}$ \\ M. Yusuf Effendy ${ }^{2}$ \\ Hamzah Hartono ${ }^{3}$ \\ E-mail:free.junaidi@gmail.com,hmzh_ic@yahoo.com,tulussukaryadi@gmail.com, \\ krispurnomo85@yahoo.com, heri_wahyudi1945@yahoo.co.id,rizky.fierlana07@gmail.com
}

\begin{abstract}
ABSTRAK
Tenaga kerja merupakan aset paling penting bagi perusahaan. Untuk menentukan kualitas karyawan, haruslah melalui proses pengajaran, pelatihan dan pengujian. Tidak semua perusahaan memiliki standar kemampuan yang bisa dijadikan tolak ukur, hal ini penting, karena dapat mengakibatkan informasi tentang kemampuan hanya berdasarkan prediksi yang bersifat subjektif, sehingga bisa terjadi kesalahan penempatan, maka diperlukan sistem penilaian kuis product knowledge yang mampu membantu proses penempatan karyawan berdasarkan penguasaan dan kemampuan yang tersimpin dengan baik dengan basis pengetahuan, sehingga dapat mendukung pengambil keputusan dalam penempatan karyawan agar sesuai dengan fungsi dan tujuan organisasi. Proses penilaian kemampuan dan penguasaan dilakukan dengan serangkaian pertanyaan secara berkala dalam bentuk kuis yang tersimpan dengan baik. Pertanyaan dan kasus dibuat sedemikian rupa sesuai dengan kebutuhan. Dan yang terpenting dari semua ini adalah adanya pengelolaan data yang baik dalam bentuk basis data yang handal, sehingga kapanpun dibutuhkan sistem mampu menjawab dengan cepat dan akurat serta dapat menciptakan efisiensi yang tinggi.
\end{abstract}

Kata Kunci: penilaian kuis, product knowladge, pendukung keputusan.

\section{PENDAHULUAN}

\subsection{Latar Belakang}

Teknologi komputer saat ini sangat penting dan sangat diperhatikan terutama untuk kalangan perusahaan berkembang. Adanya kebutuhan karyawan dan perlunya penilaian yang cepat dan akurat dan terkait dengan efisiensi waktu kerja dan biaya, yang berhubungan erat dengan gaji atau pendapatan, maka diperlukan pengembangan dan penyempurnaan terhadap sistem yang telah ada dengan memperbaiki dari kekurangannya dan melakukan pengembangan dan penyempurnaan dari sistem yang sudah ada dan masih dianggap layak.

Mengingat semakin meningkatnya jumlah karyawan pada suatu perusahaan, dan semakin rumitnya sistem pengolahan data pada bagian divisi pengembangan sumber daya manusia serta untuk menghindari kesalahan dalam proses penilaian, maka perlu diciptakan suatu sistem pengolahan data secara terkomputerisasi. Proses pembuatan kusi product knowledge termasuk dengan sistem penilaian dan rekapitulasinya.
Sistem ini diharapkan mampu melakukan proses penciptaan kuis product knowledge dengan cepat dan sesuai kebutuhan bagian atau posisi, selain itu sistem juga harus mampu melakukan random soal dan sharing soal dengan beberapa kebutuhan, setelah itu sistim juga harus mampu melakukan proses penilaian dan rekapitulasi dengan cepat dan akurat, serti tersimpan dengan baik sebagai basis data yang dapat digunakan dan kemudian ketika dibutuhkan untuk keperluan proses penilaian kinerja karyawan.

\subsection{Referensi}

Menurut Kadir (2011:2), "sistem adalah sekumpulan elemen yang saling terkait atau terpadu yang dimaksudkan untuk mencapai suatu tujuan".

Menurut Al-Jufri (2011:8), "data adalah kenyataan yang menggambarkan suatu kejadian-kejadian dan kesatuan nyata".

Menurut Sutabri (2012:29), "informasi adalah data yang telah diklasifikasi atau diinterpretasi untuk digunakan dalam proses pengambil keputusan".

Menurut Sutabri (2012:38), "nilai informasi adalah pengukuran nilai informasi 
biasanya dihubungkan dengan analsis cost effectivess atau cost benefit".

Menurut Sutabri (2012:46), “sistem informasi adalah Suatu sistem didalam suatu organisasi yang mempertemukan kebutuhan pengolahan transaksi harian yang mendukung fungsi operasi organisasi yang bersifat manajerial dengan kegiatan strategi dari suatu organisasi untuk dapat menyediakan laporan laporan yang diperlukan".

Menurut Sutabri (2012:220), "tahap analisis sistem dilakukan setelah tahap investigasi sistem dan sebelum tahap rancangan sistem, tahap analisis sistem merupakan tahap yang kritis dan sangat penting karena kesalahan ditahap ini akan menyebabkan kesalahan pada tahap selanjutnya".

Menurut Henderi, dkk dalam jurnal CCIT Vol 4 (2011:322), "Tahapan analisa sistem adalah tahap penguraian dari suatu sistem yang utuh kedalam bagian-bagian komponennya dengan maksud untuk mengidentifikasikan dan mengevaluasi permasalah - permasalahan, kesempatan-kesempatan, hambatan - hambatan yang terjadi dan kebutuhan-kebutuhan yang diharapkan sehingga dapat di buat rancangan sistem yang baru sesuai dengan kebutuhan".

Menurut Alexander Kossiakof dkk (2011:3) didefinisikan sebagai "untuk memimpin, mengelola atau langsung biasanya didasarkan pada pengalaman unggul mengejar program tertentu" dan menunjukkan jalan.

Menurut Untara (2014:282) kuis adalah ujian lisan atau tertulis yg singkat; acara hiburan $\mathrm{dl}$ radio atau televisi yg berupa perlombaan adu cepat menjawab pertanyaan; cepat tepat; cerdas cermat; (dl majalah) daftar pertanyaan sederhana yg berhadiah (kadangkadang mengandung promosi dagang).

Menurut Susanti dan Kustijana (2010:4) Product Knowlegde dikelompokkan menjadi dua dimensi yaitu pengetahuan objektif subjektif. Variabel dependen ada dua yaitu evaluasi produk dan niat pembelian. Niat pembelian (purchase intent) adalah kecenderungan konsumen untuk bertindak terhadap suatu objek Niat pembelian ini mengarah kepada tujuan (niat) yaitu kecenderungan konsumen untuk membeli merek yang paling disukainya.

Menurut Chr. Jimmy L. Gaol dalam Lindawati (2014:38) "Database adalah kumpulan datanya, sedangkan program pengelolaannya berdiri sendiri dalam satu paket program yang komersial untuk membaca data, menghapus data dan melaporkan data dalam database".

\section{PEMBAHASAN}

\subsection{Use Diagram}

Untuk mendapatkan hasil yang sesuai maka penelitian ini dilakukan studi kasus pada PT. Aora TV Satelit, dan sebagai gambaran awal mengenai proses apa yang dikerjakan dan siapa yang mengerjakan serta untuk siapa hasil yang diharapkan, maka dapat digambarkan dalam sebuah rancangan sistem secara keseluruhan dalam bentuk use case diagram (lihat gambar 1).

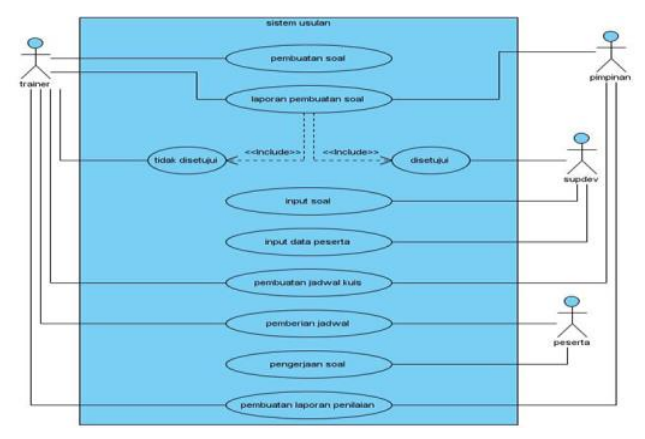

Gambar 1. Use Case Diagram

Usecase diagram sistem kuis product knowlegde diatas terdiri dari 4 actor yaitu trainer, supdev, pimpinan, dan karyawan. Dan juga mempunyai 3 behavior atau kebiasaan diantaranya yaitu prosedur pembuatan soal, prosedur input soal, prosedur pembuatan jadwal, prosedur pengerjaan soal dan prosedur pembuatan laporan.

Trainer membuat soal untuk peserta / karyawan dengan ketentuan sesuai aturan yang ada pada setiap divisi, soal yang sudah dibuat oleh trainer dilaporkan kepada pimpinan untuk dilakukan pengecekan kembali, jika soal tidak sesuai dengan kemauan pimpinan makan soal tersebut akan dibuat ulang oleh trainer.

Soal yang sudah dibuat oleh trainer dan sudah disetujui oleh pimpinan diserahkan kepada supdev agar dapat dimasukkan kedalam sistem, yang nantinya akan berguna dalam mengakses soal saat peserta mengerjakan.

Dalan kurun waktu tertentu dilakukan proses membuat jadwal kuis untuk karyawan, setelah itu diberikan kepada trainer, trainer menginformasikan kepada peserta perihal jadwal kuis bulanan 
Setelah peserta mendapat jadwal kuis yang diberikan oleh trainer, peserta segera mengerjakan kuis sesuai dengan jadwal yang diberikan, setiap peserta harus login terlebih dahulu sebelum mengerjakan soal kuis bulanan, peserta diwajibkan menjawab minimal 8 soal benar dari 10 soal yang diberikan, setelah peserta selesai mengerjakan soal kuis, hasil dari soal tersebut dapat langsung dilihat oleh peserta itu sendiri.

Trainer mereview seluruh hasil kuis yang telah dikerjakan oleh peserta, dikategorikan menurut divisi, setelah itu trainer membuat laporan penilaian yang akan diserahkan kepada pimpinan. Berdasarkan laporan inilah pimpinan dapat melakukan analisis dan kajian sehingga dengan cepat dapat melakukan proses penilaian karyawan yang dapat membantu dalam pengambilan keputusan.

\subsection{Activity Diagram}

Jika pada gambar 1 merupakan use diagram yang berfungsi untuk mengetahui siapa dan apa yang dikerjakan, maka tahapan selanjutnya adalah mengetahui bagaimana urutan pengerjaan sesungguhnya sesuai dengan use diagram yang telah digambarkan (gambar 1) dalam sebuah diagram activity (lihat gambar 2).

Dalam activity diagram ini tetap melibatkan 4 aktor yang ada pada use case diagram yang akan menjadi satu kolom pada activity diagram, dan secarat berurutan kesamping adalah actor trainer, actor pimpinan, aktor superdv dan aktor peserta. Setiap aktor tentunya memiliki tugas masing - masing sesuai dengan fungsinya, dan saling berkaitan antara satu tugas dengan tugas lainnya yang ditangani oleh setiap aktor. Aktifitas ini diawali dengan sebuah initial node oleh trainer dalam dan akan berakhir di pimpinan dengan sebuah initial node final (lihat activity diagram gambar 2).

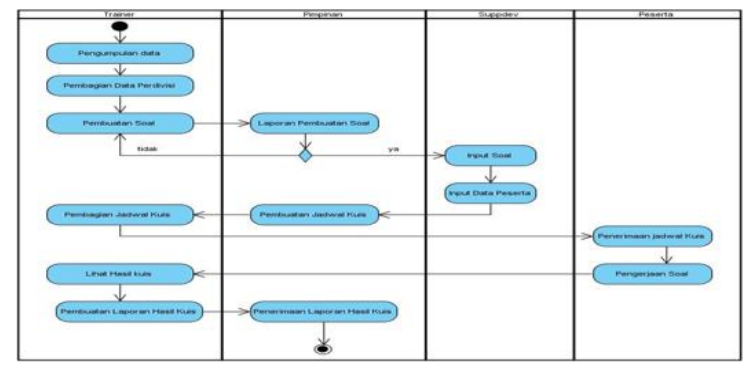

Gambar 2. Activity Diagram
Terdapat tiga belas activity sebagai state yang mencerminkan aksi dari suatu system. Diawali dari trainer dalam pengumpulan yang kemudian dilakukan pengelompokkan data berdasarkan jenis kebutuhan, dan berdasarkan penglompokan data maka dibuatlah soal kuis sebagai bentuk product knowledge, soal yang telah dibuat kemudian akan diajukan kepada pimpinan untuk mendapatkan masukan dan arahan serta persetujuan.

Sampai dengan tahapan diatas maka akan masuk pada tahapan decision node untuk menentukan apakah soal yang telah dibuat bias dilanjutkan atau tidak, jika pada tahapan ini ternyata soal belum disetujui maka proses akan kembali pada trainer untuk dilakukan penyesuaian, dan jika soal yang telah dibuat sesuai dengan harapan maka langkah selanjutnya adalah akan dilakukan proses penginputan soal kedalam system dan akan disimpan pada basisdata sebagai bentuk product knowledge yang dilakukan oleh superdev

Selanjutnya soal yang telah tersimpan akan dikaitkan dengan bagian dan karyawan yang akan menjadi peserta, sehingga diharapkan akan terjadi random soal sehingga setiap peserta pasti mendapatkan soal yang berbeda dalam waktu yang bersaamaan akan tetapi tetap memliki unsur penilaian dengan tujuan yang sama. Setelah proses pembuatan soal ini, maka langkah selanjutnya adalah melakukan pembuatan jadwal bagi setiap peserta, jadwal yang telah dibuat sedemikian rupa akan didistribusikan langsung kepada peserta agar peserta dapat langsung mengerjakan sesuai dengan waktu yang telah ditentukan. Kemudian hasil dari pengerjaan soal setiap peserta akan dilakukan penilaian oleh trainer, dan hasilnya akan dilaporkan kepada pimpinan dalam bentuk rekpitulasi penilaian, berdasarkan laporan ini pimpinan diharapkan merasa terbantu untuk menentukan kinerja karyawan dengan cepat dan akurat.

\subsection{Squence Diagram}

Gambaran yang jelas untuk urutan pengerjaan ini dapat dilihat dengan lengkap pada sequence diagram (gambar 3). Diagram diatas menggambarkan sequence diagram sistem kuis product knowledge ini melibat empat actor yang melakukan kegiatan yaitu trainer, supdev, peserta dan pimpinan, dan lima lifeline yang menghubungkan seluruh prosedur sistem, serta empat belas message yang 
menggambarkan alur dari sistem kuis product knowledge.

Tahapan pengumpulan data, pendataan peserta dan dilanjutkan dengan pembutan soal kuis product knowledge dilakukan terlebih dahulu secara berurutan oleh trainer, yang kumudian diajukan kepada pimpinan untuk mendapatkan persetujuan, dan setelah disetujuan baru dilakukan proses penginputan soal dan penginputan data peserta. Setelah keduanya ini dilakukan maka barulah tahapan pembuatan jadwal oleh trainer dapat dilakukan setelah laporan pembuatan soal disampaikan kepada pimpinan yang kemudian pimpinan memberikan arahan untuk melakukan pembuatan jadwal kuis yang akan dikerjakan peserta.

Sampai dengan tahapan pembuatan jadwal maka dapat dipastikan setiap peserta akan mengerjakan soal sesuai jadwalnya, dan hasil setiap pengerjaan ini secara otomatis akan tersimpan dalam sebuah basis data kuis product knowledge (lihat gambar 3).

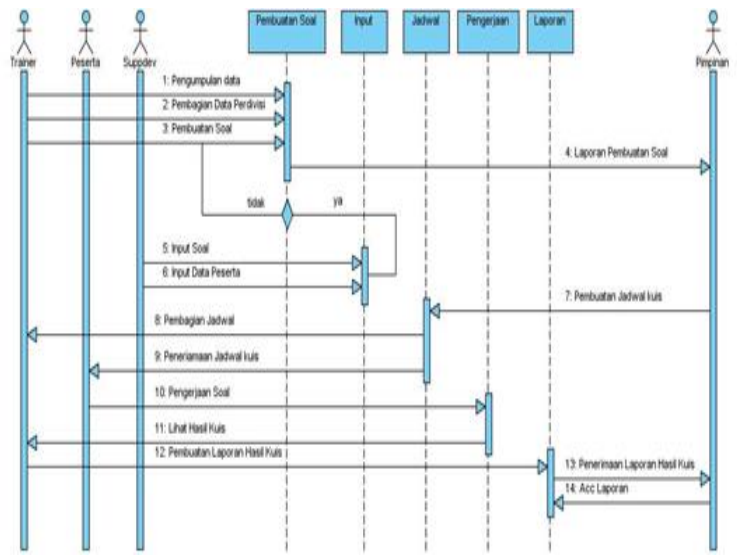

Gambar 3. Squence Diagram

Pimpinan bisa kapan saja memuta kepada trainer untuk mendapatkan laporan rekapitulasi penilaian jika dibutuhkan, dan secara otomatis tentunya trainer dapat dengan cepat melakukan apa yang diminta, dan pimpinan pasti mendapatkan hasil yang akurat, sehingga dapat membantu pimpinan dalam proses penentuan kinerja karyawan dengan cepat dan tepat pula. Hal ini sangat dibutuhkan dan berpengaruh terhadap kinerja perusahaan, karena selain cepat, tepat dan akurat, juga pastinya dapat meningkatkan efisiensi beberapa kali lipat, dari yang seblumnya dilakukan secara manual.

\subsection{Class Diagram}

Inti dari semua yang dilakukan akan sempurna dan terasa manfaatnya jika memiliki basis data yang baik dan kuat. Basis data merupakan jantung dari system ini, karena semua informasi soal, jadwal pengerjaan, siapa dan apa yang dikerjakan serta berapa nilai yang dihasilkan setiap peserta hanya dapat diciptakan jika memiliki basis data yang sangat baik. Gambaran dari basis data kuis product knowledge ini dapat digambarkan dalam sebuah kelas diagram (gambar 4).

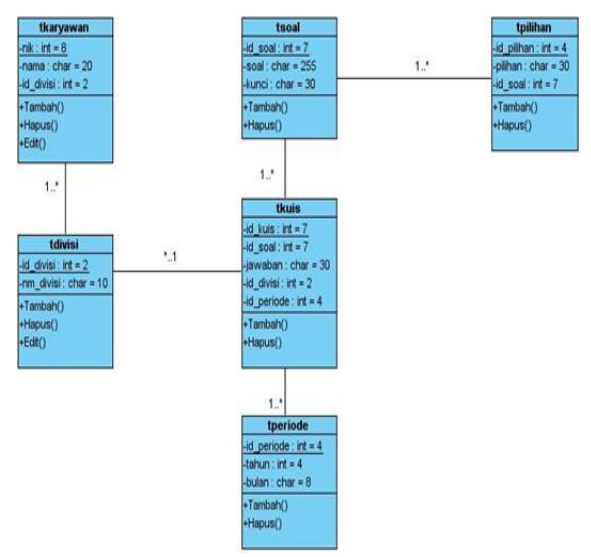

Gambar 4. Class Diagram

Untuk memperkuat basis data agar kuis product knowledge dapat bekerja sebagaimana mestinya, maka diperlukan 4 buah tabel master yaitu karyawan, divisi dan periode, selain itu juga disertakan tabel pilihan sebagai informasi pilihan jawaban untuk setiap soal yang dibuat.

Secara garis besar tabel karwan minimal memiliki informasi nomor induk dan nama, serta memilik satu simpul informasi untuk kode divisi. Kode divisi ini kemudian akan dihubungkan dengan tabel divisi untuk mendapatkan informasi yang ada pada tabel divisi sesuai dengan kode divisi yang dimiliki karyaran, sementara tabel divisi sendiri minimal memiliki kode dan nama divisi. Sementara tabel master periode dan tabel master pilihan akan berguna saat proses penginputan soal dilakukan.

Tabel soal merupakan media penyimpanan semua soal yang dibuat, dan pilihan setiap soal akan disimpan pada tabel pilihan, teknik memisahkan tabel soal dan tabel pilihan ini dimaksudkan agar soal dapat dilakukan secara random termasuk dalam memunculkan pilihan 
setiap soal, sehingga baik soal maupun pilihan bisa digunakan secara bersama - sama dan saling pakai. Selain dari soal dan pilihannya juga terdapat informasi jawaban setiap soal, hal ini sangat penting keberadaanya agar sistem secara otomatis mampu memerikan jawaban dengan cepat apakah soal yang dikerjakan peserta benar atau salah jawabannya.

Setelah tabel soal dan pilihannya, terdapat juga tabel periode dan kuis, kedua tabel ini merupakan tabel yang akan menentukan histori setiap soal yang diberikan dan dikerjakan pada setiap periode waktu, keberadaan tabel periode sangat dibutuhkan agar sistem mampu memberikan informasi laporan pengerjaan soal oleh karyawan sesuai periode yang dibutuhkan dalam bentuk rekapitulasi. Sementara tabel akan menyimpan informasi tentang siapa yang mengerjakan, dan soal apa yang dikerjakan serta jawaban apa yang diberikan.

\subsection{Basis Data}

Perhatikan tabel 1, merupakan tabel yang diperuntukkan untuk data karyawan atau peserta yang akan mengerjakan kuis product knowledge, terdapat tiga field yang terdiri dari dua sebagai field utama dan satu diantanya merupakan primary key (pk) yaitu nik (nomor induk karyawan), dan satu lagi merupakan foreign key (fk) yaitu id_divisi yang didapat dari tabel divisi.

Tabel 1. Karyawan

\begin{tabular}{|c|l|c|c|c|}
\hline $\begin{array}{l}\text { N } \\
\text { o }\end{array}$ & Field & $\begin{array}{c}\text { Tipe } \\
\text { Field }\end{array}$ & $\begin{array}{c}\text { Panjan } \\
\text { g }\end{array}$ & $\begin{array}{c}\text { Keterang } \\
\text { an }\end{array}$ \\
\hline 1 & Nik & Int & 8 & $\begin{array}{c}\text { PrimaryKe } \\
\text { y }\end{array}$ \\
\hline 2 & Nama & $\begin{array}{c}\text { Varcha } \\
\text { r }\end{array}$ & 20 & - \\
\hline 3 & $\begin{array}{l}\text { Id } \\
\text { Divisi }\end{array}$ & Int & 2 & $\begin{array}{c}\text { Foreign } \\
\text { Key }\end{array}$ \\
\hline
\end{tabular}

Perhatikan tabel 2, merupakan tabel yang diperuntukkan untuk data divisi yang merupakan acuan dari pengelompokan soal kuis product knowledge, terdapat dua field utama yaitu id_divisi dan nm_divisi, dan satu diantaranya yaitu id_divisi merupakan primary key (pk), tabel ini tidak memiliki foreign key (fk) yang merujuk pada tabel lain.
Tabel 2. Divisi

\begin{tabular}{|c|c|c|c|c|}
\hline $\begin{array}{l}\text { N } \\
\text { o }\end{array}$ & Field & $\begin{array}{c}\text { Tipe } \\
\text { Field }\end{array}$ & $\begin{array}{c}\text { Panjan } \\
\text { g }\end{array}$ & $\begin{array}{c}\text { Keterang } \\
\text { an }\end{array}$ \\
\hline 1 & id_divi & Int & 2 & $\begin{array}{c}\text { PrimaryKe } \\
\mathrm{y}\end{array}$ \\
\hline 2 & $\begin{array}{c}\text { nm_di } \\
\text { si }\end{array}$ & $\begin{array}{c}\text { Varcha } \\
\text { r }\end{array}$ & 10 & - \\
\hline
\end{tabular}

Perhatikan tabel 3, merupakan tabel yang diperuntukkan untuk bank soal kuis product knowledge, terdapat tiga field utama yaitu id_soal, soal dan kunci jawaban, dan satu diantaranya yaitu id_soal merupakan primary key (pk), tabel ini tidak memiliki foreign key (fk) yang merujuk pada tabel lain.

Tabel 3. Soal

\begin{tabular}{|c|l|c|c|c|}
\hline $\begin{array}{c}\text { N } \\
\mathbf{o}\end{array}$ & Field & $\begin{array}{c}\text { Tipe } \\
\text { Field }\end{array}$ & $\begin{array}{c}\text { Panjan } \\
\mathbf{g}\end{array}$ & $\begin{array}{c}\text { Keterang } \\
\text { an }\end{array}$ \\
\hline 1 & id_soal & Int & 7 & $\begin{array}{c}\text { PrimaryKe } \\
\mathrm{y}\end{array}$ \\
\hline 2 & soal & $\begin{array}{c}\text { Varcha } \\
\mathrm{r}\end{array}$ & 255 & - \\
\hline 3 & kunci & $\begin{array}{c}\text { Varcha } \\
\mathrm{r}\end{array}$ & 30 & - \\
\hline
\end{tabular}

Perhatikan tabel 4, merupakan tabel yang diperuntukkan untuk data pilihan jawaban kuis product knowledge, terdapat tiga field yang terdiri dari dua sebagai field utama dan satu diantanya merupakan primary key (pk) yaitu id_pilihan, dan satu lagi merupakan foreign key (fk) yaitu id_soal yang didapat dari tabel soal. Dalam hal ini satu tabel soalakan memiliki beberapa jawaban.

Tabel 4. Pilihan

\begin{tabular}{|c|l|c|c|c|}
\hline $\begin{array}{c}\text { N } \\
\text { o }\end{array}$ & \multicolumn{1}{|c|}{ Field } & $\begin{array}{c}\text { Tipe } \\
\text { Field }\end{array}$ & $\begin{array}{c}\text { Panja } \\
\text { ng }\end{array}$ & $\begin{array}{c}\text { Keterang } \\
\text { an }\end{array}$ \\
\hline 1 & $\begin{array}{l}\text { id_pilih } \\
\text { an }\end{array}$ & Int & 4 & $\begin{array}{c}\text { PrimaryK } \\
\text { ey }\end{array}$ \\
\hline 2 & pilhan & $\begin{array}{c}\text { Varcha } \\
\text { r }\end{array}$ & 30 & - \\
\hline 3 & id_soal & Int & 7 & $\begin{array}{c}\text { Foreign } \\
\text { Key }\end{array}$ \\
\hline
\end{tabular}

Perhatikan tabel 5, merupakan tabel yang diperuntukkan untuk mencatat history pengerjaan kuis product knowledge, terdapat tiga field utama yaitu id_periode, tahun dan bulan, dan satu diantaranya yaitu id_periode merupakan primary key (pk), tabel ini tidak 
memiliki foreign key (fk) yang merujuk pada tabel lain.

Tabel 5. Periode

\begin{tabular}{|c|l|c|c|c|}
\hline $\begin{array}{l}\text { N } \\
\text { o }\end{array}$ & \multicolumn{1}{c|}{ Field } & $\begin{array}{c}\text { Tipe } \\
\text { Field }\end{array}$ & $\begin{array}{c}\text { Panja } \\
\text { ng }\end{array}$ & $\begin{array}{c}\text { Keterang } \\
\text { an }\end{array}$ \\
\hline 1 & $\begin{array}{l}\text { id_perio } \\
\text { de }\end{array}$ & Int & 4 & $\begin{array}{c}\text { PrimaryK } \\
\text { ey }\end{array}$ \\
\hline 2 & tahun & Int & 4 & - \\
\hline 3 & bulan & $\begin{array}{c}\text { Varcha } \\
\text { r }\end{array}$ & 8 & $\begin{array}{c}\text { Foreign } \\
\text { Key }\end{array}$ \\
\hline
\end{tabular}

Perhatikan tabel 6, merupakan tabel yang diperuntukkan untuk data pengerjaan soal kuis product knowledge, terdapat lima field yang terdiri dari dua sebagai field utama yang merupakan jawaban atas pengerjaan soal yaitu jawaban, dan 4 field merupakan foreign key (fk) yaitu id_kuis, id_soal, id_divisi dan id_periode. Data ini sangat dibutuhkan karena menyimpan informasi siapa yang mengerjakan, berapa hasil yang diperoleh, soal apa yang dikerjakan dan kapan dikerjakan.

Tabel 6. Kuis

\begin{tabular}{|c|l|c|c|c|}
\hline $\begin{array}{l}\text { N } \\
\text { o }\end{array}$ & Field & $\begin{array}{c}\text { Tipe } \\
\text { Field }\end{array}$ & $\begin{array}{c}\text { Panja } \\
\text { ng }\end{array}$ & $\begin{array}{c}\text { Keterang } \\
\text { an }\end{array}$ \\
\hline 1 & id_kuis & Int & 7 & $\begin{array}{c}\text { PrimaryK } \\
\text { ey }\end{array}$ \\
\hline 2 & id_soal & Int & 7 & $\begin{array}{c}\text { Foreign } \\
\text { Key }\end{array}$ \\
\hline 3 & Jawaban & $\begin{array}{c}\text { Varcha } \\
\text { r }\end{array}$ & 30 & - \\
\hline 4 & id_divisi & Int & 2 & $\begin{array}{c}\text { Foreign } \\
\text { Key }\end{array}$ \\
\hline 5 & $\begin{array}{l}\text { id_perio } \\
\text { de }\end{array}$ & Int & 4 & $\begin{array}{c}\text { Foreign } \\
\text { Key }\end{array}$ \\
\hline
\end{tabular}

\subsection{Flowchart Program}

Untuk dapat memberikan gambaran cara kerja program dapat dilihat pada gambar 5 yang merupakan bagaimana alur program dijalankan.

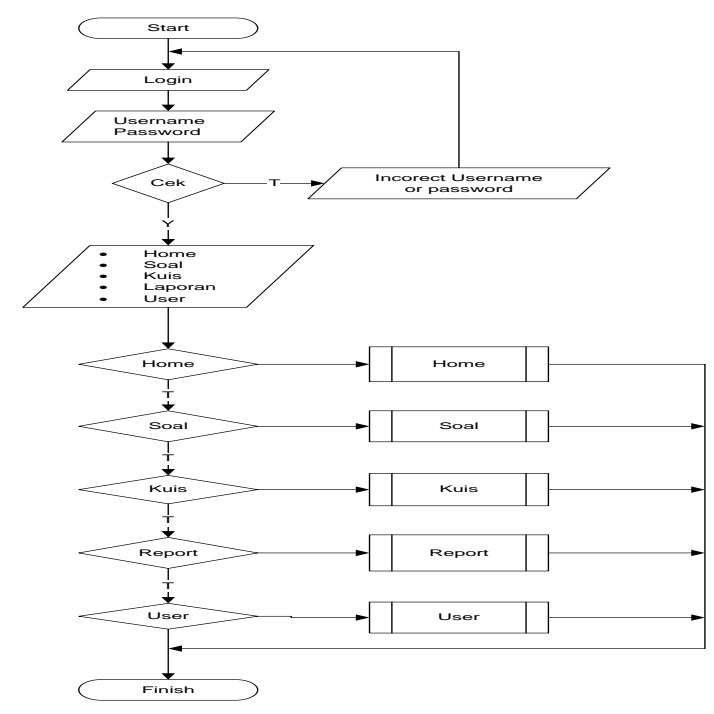

Gambar 5. Squence Diagram

Flowchart program tersebut akan melibatkan 2 (dua) simbol terimal, yang berperan sebagai "start" dan "finish" pada aliran proses flowchart program di login admin, melibatkan 3 (tiga) simbol data, yang menyatakan proses input atau output tanpa tergantung jenis peralatannya, yaitu "login" kemudia untuk login admin memasukan "username dan password", dan jika salah sistem akan memberikan data yang bertuliskan "incorrect username or password", selain itu juga melibatkan 1 (satu) simbol decision, sebagai simbol untuk menunjukan sebuah langkah pengambilan keputusan untuk pengecekan validasi kebenaran username dan password, jika "ya" akan bisa langsung masuk ke home admin jika "tidak" akan kembali ke menu login, juga melibatkan 5 (lima) symbol sub proses sebagai simbol yang menunjukan bahwa didalam langkah yang dimaksud terdapat flowchart lain yang akan menggambarkan langkah secara rinci, yang terdiri dari 5 (lima) macam-macam menu yaitu menu home, menu soal, menu kuis, menu report dan menu user. 
Gambar 6 merupakan flowchart soal pada sistem kuis produk knowledge, melibatkan 2 (dua) symbol terminal, yang berperan sebagai "start" dan "finish" pada aliran proses flowchart program pada menu soal.

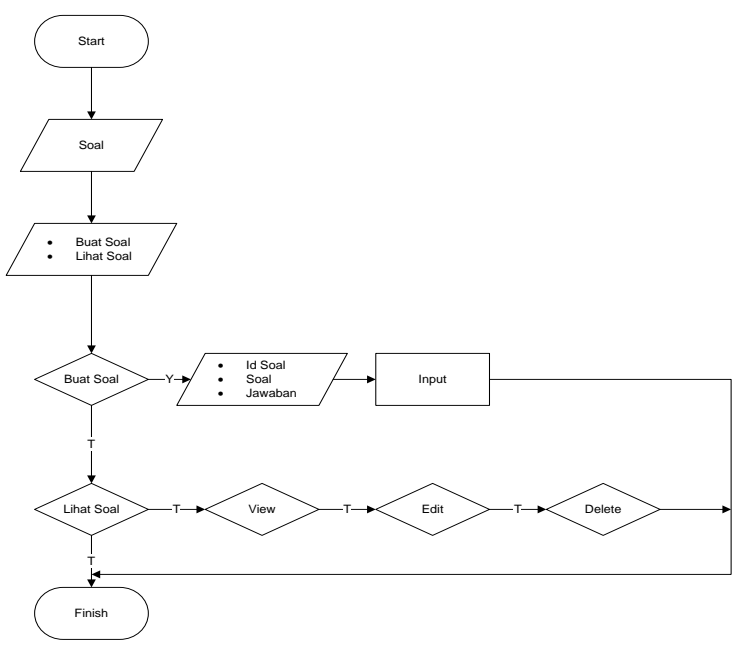

Gambar 6. Squence Diagram

Flowchart ini melibatkan 1 (satu) simbol data, yang menyatakan proses input atau output tanpa tergantung jenis peralatannya, melibatkan 5 (lima) symbol decision, yang berperan untuk menunjukan sebuah langkah pengambilan keputusan antara "ya" dan "tidak", serta melibatkan 1 (satu) symbol proses, yang menyatakan diprosesnya masukan soal

Gambar 7 merupakan flowchart soal pada sistem kuis produk knowledge, melibatkan 2 (dua) symbol terminal, yang berperan sebagai "start" dan "finish" pada aliran proses flowchart program pada menu soal, melibatkan 2 (satu) simbol data, yang menyatakan proses input atau output tanpa tergantung jenis peralatannya, 5 (lima) symbol decision, yang berperan untuk menunjukan sebuah langkah pengambilan keputusan antara "ya" dan "tidak", serta 5 (satu) symbol proses, yang menyatakan diprosesnya masukan data kuis.

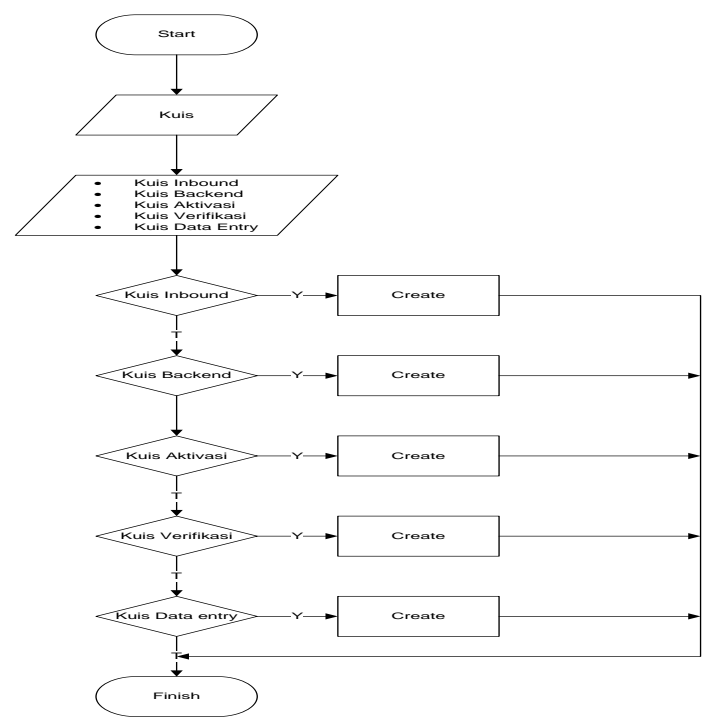

Gambar 7. Squence Diagram

Gambar 8 flowchart report pada "rekayasa sistem kuis produk knowledge, melibatkan 2 (dua) symbol terminal, yang berperan sebagai "start" dan "finish" pada aliran proses flowchart program pada menu report, 4 (empat) simbol data, yang menyatakan proses input atau output tanpa tergantung jenis peralatannya, 2 (dua) symbol decision, yang berperan untuk menunjukan sebuah langkah pengambilan keputusan antara "ya" dan "tidak", 4 (empat) symbol proses, yang menyatakan proses dari laporan.

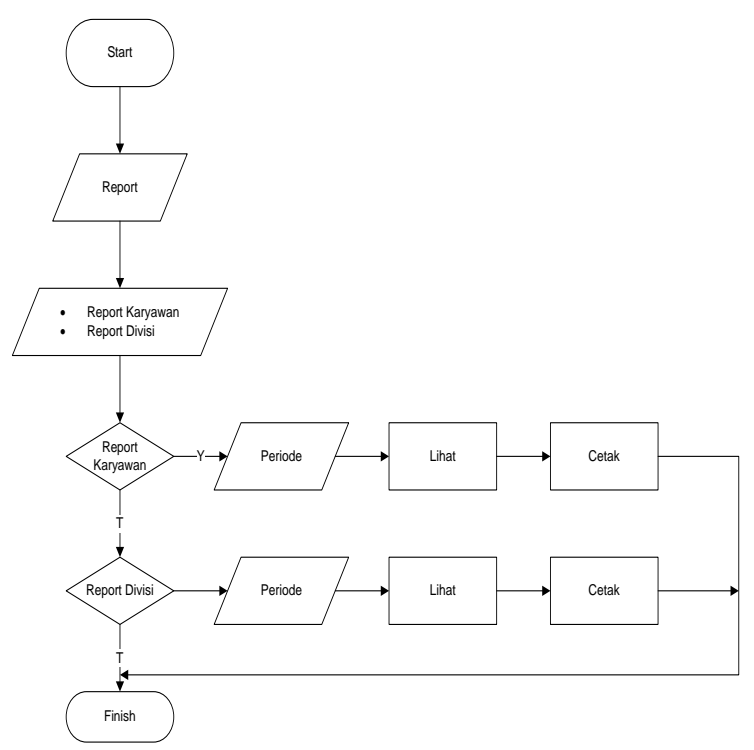

Gambar 8. Squence Diagram 
Gambar 9 flowchart login karyawan pada "rekayasa sistem kuis produk knowledge", melibatkan 2 (dua) symbol terimal, yang berperan sebagai "start" dan "finish" pada aliran proses flowchart program pada login admin, 3 (tiga) symbol data, yang menyatakan proses input atau output tampa tergantung jenis peralatannya, yaitu "login" kemudia untuk login admin memasukan "username dan password", dan jika salah sistem akan memberikan data yang bertuliskan "Incorrect username or password", 3 (tiga) symbol decision, sebagai symbol untuk menunjukan sebuah langkang pengambilan suatu keputusan antara "ya" dan "tidak", 1 (satu) symbol proses, sebagai symbol untuk menunjakan bahwa karyawan/peserta mengerjakan soal.

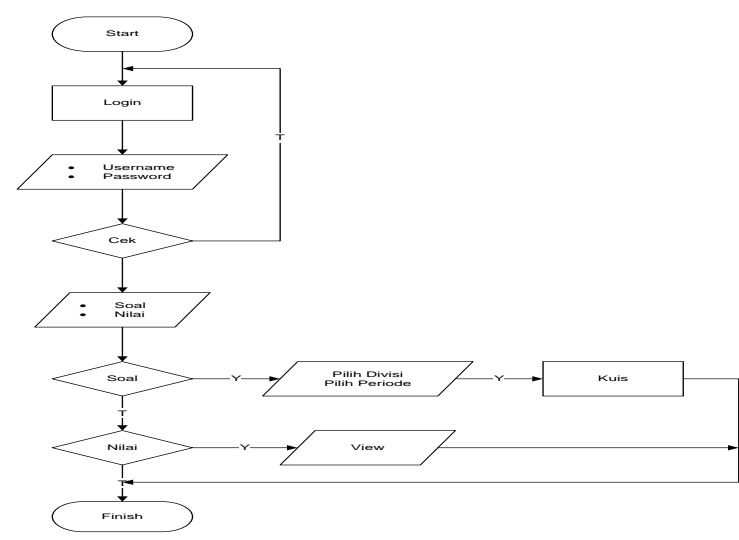

Gambar 9. Squence Diagram

Gambar 10 flowchart login pimpinan pada "rekayasa sistem kuis produk knowledge" melibatkan 2 (dua) symbol terimal, yang berperan sebagai "start" dan "finish" pada aliran proses flowchart program pada login admin, 5 (lima) symbol data, yang menyatakan proses input atau output tampa tergantung jenis peralatannya, 3 (tiga) symbol decision, sebagai symbol untuk menunjukan sebuah langkang pengambilan suatu keputusan antara "ya" dan "tidak", 1 (satu) symbol proses, sebagai symbol untuk menunjakan bahwa pimpinan sudah menyetujui soal.

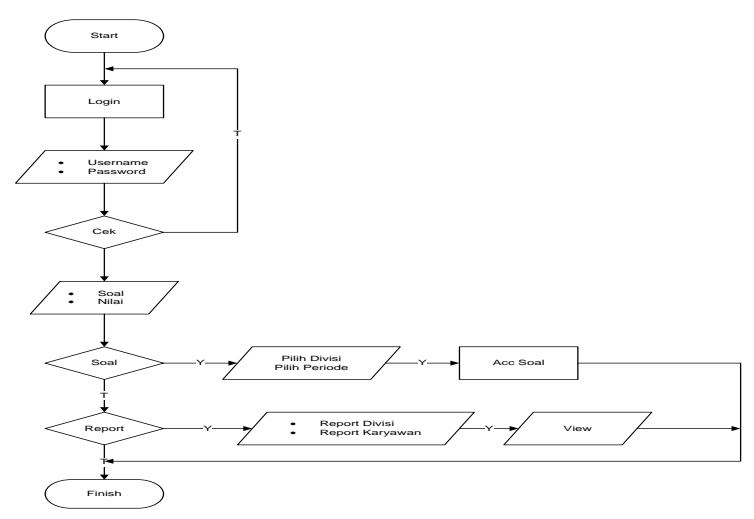

Gambar 10. Squence Diagram

\subsection{Diagram HIPO}

HIPO (hirarchy plus input process output) yaitu alat bantu untuk membuat spesifikasi program yang merupakan struktur yang berisi diagram. Di dalam program ini berisi input yang diproses dan menghasilkan output. Spesifikasi program menjelaskan megenai cara penggunaan aplikasi program yang diusulkan. Visual table of content (VTOC) adalah diagram yang menggambarkan hubungan dan fungsi pada sistem secara berjenjang (gambar 11).

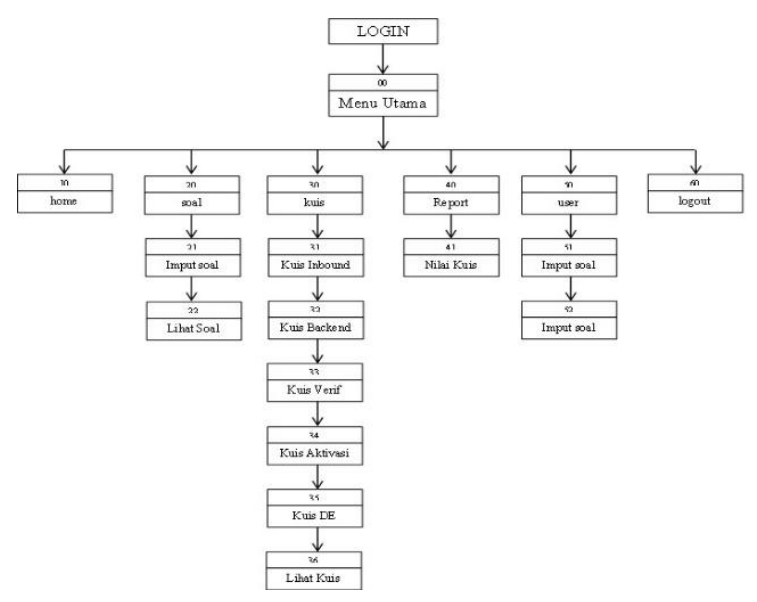

Gambar 11. Diagram HIPO Admin

Gambar 12 merupakan hirarchy plus input process output untuk karyawan.

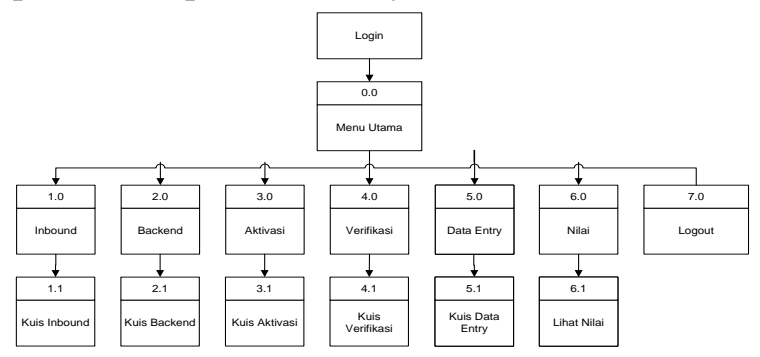

Gambar 12. Diagram HIPO Karyawan 
Gambar 13 merupakan hirarchy plus input process output untuk pimpinan.

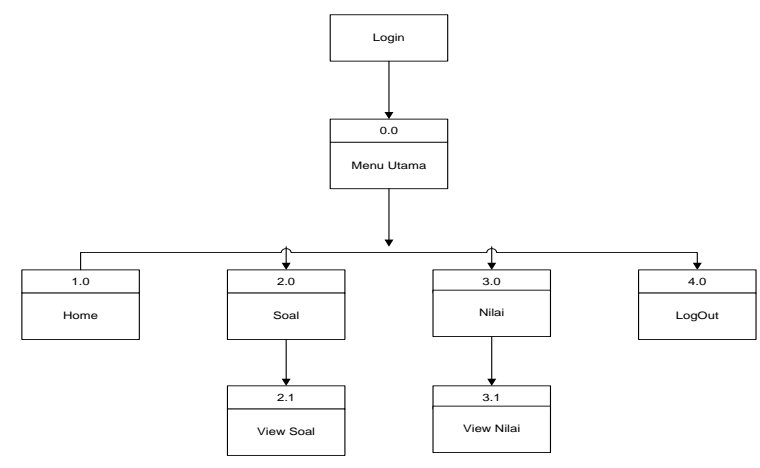

Gambar 13. Diagram HIPO Karyawan

\subsection{Prototype}

Berdasarkan diagram HIPO maka dapat diciptakan sebuah prototype model unutk layar dialog sistem dengan user dalam melakukan implementasi kuis product knowledge. Gambar 14 merupakan prototype dari sistem sebenarnya yang akan dibuat untuk admin.

\begin{tabular}{|c|c|c|}
\hline \multicolumn{2}{|c|}{ Aora TV } & Welcome \\
\hline Home & \\
\cline { 1 - 1 } Soal & \\
\cline { 1 - 1 } Kuis & \\
\cline { 1 - 1 } User & \\
\hline Report & \\
\cline { 1 - 1 } Logout & \\
\hline
\end{tabular}

Gambar 14. Diagram HIPO Karyawan

Gambar 15 merupakan prototype dari sistem sebenarnya yang akan dibuat untuk karyawan.

\begin{tabular}{|l|l|l|l|l|}
\hline \multicolumn{3}{|c|}{ Aora TV } & Welcome \\
\hline Inbound & Backend & Aktifasi & Verifikasi & Data Entri \\
\hline \multicolumn{3}{|c|}{} \\
\\
\\
\end{tabular}

Gambar 15. Diagram HIPO Karyawan

Gambar 16 merupakan prototype dari sistem sebenarnya yang akan dibuat untuk pimpinan.

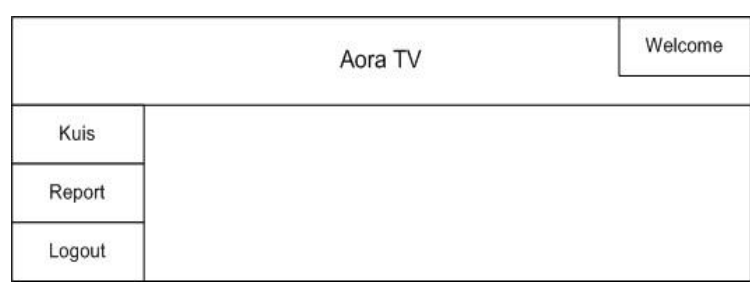

Gambar 16. Diagram HIPO Karyawan

Dari ketiga prototype diatas (gambar 14, gambar 15 dan gambar 16) dibuat berdasarkan kebutuhan sistem, dan tentunya hal ini dapat disesuaikan dengan fasilitas konfigurasi. Struktur yang digambarkan pada diagram HIPO merupakan dasar dari dibuatnya sebuah prototype, dan prototype ini nantinya akan menjadi landasan dalam perancangan sistem, termasuk juga dengan struktur database yang digambarkan pada class diagram (gambar 4). Selain itu prototype juga dibuat sedemikian rupa dengan memperhatikan prosedur yang ada atau direncanakan berdasarkan use case diagram (gambar 1), activity diagram (gambar 2) serta squuence diagram (gambar 3), hal terpenting berikutnya adalah proses pembuatan basis data.

\subsection{Testing}

Selain merancanakan sistem dalam bentuk prototype juga perlu dilakukan testing dengan menggunakan metode pengujian black box testing. black box testing adalah metode uji coba yang memfokuskan pada keperluan software. Karena itu uji coba black box memungkinkan pengembangan software untuk membuat himpunan kondisi input yang akan melatih seluruh syarat-syarat fungsional suatu program. Metode pengujian black box berusaha untuk menemukan kesalahan dalam beberapa katagori, diantaranya: fungsi-fungsi yang salah atau hilang, kesalahan dalam struktur data atau akses database eksternal, kesalahan performa, kesalahan inisialisasi, dan terminasi.

\section{Tabel 7. Black Box}

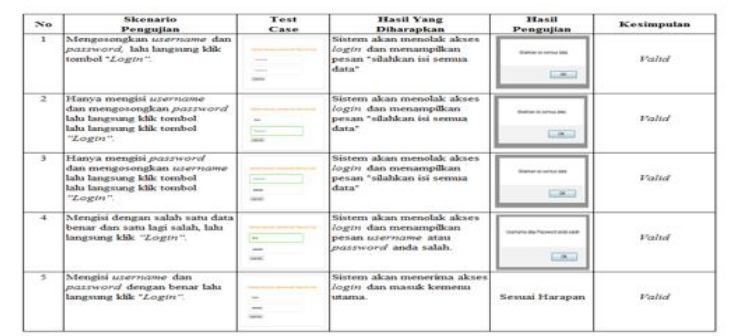


Setelah dilakukan pengujian dengan metode Black box yang dilakukan dengan cara memberikan sejumlah input pada program seperti contoh pengujian pada masing-masing menu dan sub menu. Jika input data tidak lengkap maka sistem akan menampilkan pesan dan menyampaikan pesan yang sangat membantu admin jika admin mendapati kesalahan saat input data yang tidak lengkap, kemudian akan di proses sesuai dengan kebutuhan fungsionalnya dan dapat menghasilkan output yang sesuai dengan yang diinginkan.

Selain itu pengujian juga dilakukan terhadap keabsahan data, baik pada saat pembuatan soal, penentuan jawaban juga proses pengacakan soal. dengan konsep basis data yang dibuat, diharapkan mampu meminimalisir kesalahan, baik untuk pengguna pada saat implementasi kusi product knowledge, maupun pada saat melakukan rekapitulasi data untuk pimpinan, sehingga data yang disajikan benar benar mampu memberikan masukan dalam mendukung proses pengambilan keputusan.

Pengujian juga dilakukan terhadap kesesuain soal dengan bagian, dan kesesuaian jawaban yang diberikan dengan kebutuhan bagian, karena system ini mampu memberikan informasi kinerja karyawan.

\section{KESIMPULAN}

Aplikasi sistem kuis product knowledge dapat mambantu perusahaan dalam melakukan penilaian terhadap kinerja karyawan, sekaligus mampu menciptakan knowledge base untuk seluruh karyawan. Kemampuan sistem untuk menyimpan semua history pengerjakan kuis berikut hasilnya dapat menciptakan rekapitulasi laporan kinerja karyawan, sehingga hal ini diharapkan mampu membantu para pengambil keputusan dalam penyediaan informasi yang cepat tepat dan akurat, selain itu sistem ini mampu menciptakan tingkat efisiensi yang tinggi bagi perusahaan, karena semua berjalan secara papperless.

Pengembangan model sistem kuis product knowledge ini dapat dikembangkan lebih jauh, apalagi bila digabungkan dengan konsep capaian target setiap pekerjaan, sehingga selain proses penilaian kinerja menggunakan kuis, juga dapat diperoleh dari kinerja capaian target.

\section{DAFTAR PUSTAKA}

Al-Jufri, Hamid. 2011. Sistem Informasi Manajemen Pendidikan. Jakarta: PT Smart Grafika

Hamzah. Sutoyo. 2010. Sistem Pendukung Keputusan Penilaian Kinerja Dosen Dengan Metode Balanced Scorecard, Yogyakarta: UPN-Veteran, Mei 2010.

Henderi, Maimunah, Randy Andrian. 2011. Desain Aplikasi E-learning Sebagai Media Pembelajaran Artificial Informatics.Tangerang: Jurnal CCIT. Vol. 4, No.3-Mei 2011.

Kadir, Abdul. 2011. Membuat Aplikasi Web dengan PHP dan Database MySQL. Yogyakarta: Andi Offset.

Kossiakoff, Alexander, Sweet, William N., Seymour, Samuel J., Biemer, Steven M. 2011. Systems Engineering Principles and Practice. New Jersey: John Wiley \& Sons

Rachman. Andy. 2008 Sistem Pendukung Keputusan Seleksi Sumber Daya Manusia di Perusahaan, Yogyakarta: Institut Teknologi Adhi Tama Surabaya.

Susanti, Ratna, Kustijana, Dwi Hastjarja. 2010. Efek Dari Country of Origin Dan Pengetahuan Produk Pada Evaluasi Produk dan Niat Pembelian Produk Sepeda Motor. Jurnal Ekonomi dan Kewirausahaan Vol. 10, No. 1, April $2010: 1$ - 10

Sutabri, Tata. 2012. Konsep Dasar Informasi. Yogyakarta: Andi Offset.

Untara, Wahyu. 2014. Kamus Bahasa Indonesia Edisi Revisi. Yogyakarta: Indonesia Tera.

Wijayanti, Esa. 2014. Perancangan Sistem Informasi Absensi Pegawai Pada Kantor Kecamatan Batuceper Tangerang. Tangerang: Perguruan Tinggi Raharja 